\title{
Improvisation of Mechanical Properties on Natural Rubber Latex Nanocomposites with Additioning of Cellulose Nanocrystals (CNCs) Percolated by Carbon Nanotubes (CNTs) in Various Concentrations
}

\author{
Amir Hamzah Siregar ${ }^{1}$, Saharman Gea ${ }^{2}$, Diana Alemin Barus ${ }^{3}$, Nami Panindia ${ }^{4}$, Yosatria \\ Juanka Sibarani $^{5}$, Yasir Arafat Hutapea ${ }^{6}$ \\ \{s.gea@usu.ac.id ${ }^{2}$ \} \\ University of Sumatera Utara, Medan 2015, Indonesia ${ }^{1,2,3,4,5,6}$
}

\begin{abstract}
The study on enhancing mechanical properties of natural rubber-based nanocomposites which was reinforced with nanofiller has been observed for many years. In this research, cellulose nanocrystals (CNCs), which was prepared by hydrolyzing cellulose from oil palm empty fruit bunches (OPEFB), were percolated with carbon nanotubes (CNTs) using ultrasonicator to obtain CNCs@CNTs nanohybrid and utilized as the filler. Natural rubber latex/CNCs@CNTs nanocomposites were fabricated via latex mild mixing and coagulated by sulphuric acid followed by hydraulic hot-press. The mechanical properties of natural rubber latex/CNCs@CNTs nanocomposites were characterized using the tensile testing machine to evaluate the efficiency of the filler reinforcing the nanocomposites. On the other hand, the morphology of nanocomposite was observed by Scanning Electron Microscope (SEM) and its swelling index (SI) was calculated using ASTM D3616. Tensile test showed a significant increase in tensile strength of nanocomposites with the optimum number of $0.428 \mathrm{MPa}$ and was achieved by nanocomposite consisting $3 \mathrm{phr}$ of filler. Moreover, the least number of SI was also belonged to $3 \mathrm{phr}$ filler of nanocomposites, which is 8.5 . Finally, the morphology of nanocomposites exhibited the filler taking a prominent role in improving the mechanical properties.
\end{abstract}

Keywords: Natural Rubber Latex, Cellulose Nanocrystals, Carbon Nanotubes, Nanocomposites, Mechanical Properties.

\section{Introduction}

Natural Rubber Latex (NRL) is a milky liquid produced from rubber (Hevea brasiliensis) trees, while Natural Rubber (NR) is a polymer of isoprene (cis 1,4-polyisoprene) formed from NRL (Roberts, 1988). According to the latest statistics from International Trade Centre (ICT), Indonesia has exported over $30.7 \%$ of the world's total rubber exports or equivalent to over USD 5.1 billion of worth in 2017, making Indonesia as the second largest NR exporter in the world.

Due to its excellent properties on elasticity, NR has been widely utilized as the main component in rubber industry, for instance, tires manufacturing. However, preparing NRbased product is banned by low tensile strength and abrasion resistence of NR. Therefore, improvement of NR should be conducted to incline the mechanical and physical properties 
(Roberts, 1988). One of the methods is reinforcing. NR by reinforcement agents, for example, cellulose nanocrystals (CNCs) and carbon nanotubes (CNTs).

CNCs have been used as polymer reinforcing agents due to their outstanding properties, such as strong elastic modulus, low abrasion and density, abundant, and biodegradable in nature (Zhang, et al., 2014). Another nano-filler reinforcement agent used for reducing effect on NR is CNTs. CNTs, another kind of carbon nanoparticles, have attracted many researchers to put them as filler into their composite due to their distinctive nanostructures and superlative electro-mechanical properties (Meng and Zloczower, 2015).

Enhancing transitional behavior of electrical and mechanical properties of polymerbased nanocomposite using a percolation approach have been such an interesting research in recent years. In a percolation approach, the fillers, such as CNCs and CNTs, are inserted in the composite and the critical volume fraction (percolation threshold) of the fillers are required to prevail the percolating way across thematrix (Noel, et al., 2014). Wang et al. (2015) have been successfully fabricated flexible strain sensors by tailoring percolating conductive networks of $\mathrm{NR} / \mathrm{CNT}$ via CNC. Those sensors presented up to $100 \%$ strain, high resistivity and sensitivity $(\mathrm{G} \approx 43.5)$, yet they showed a very low electrical conductivity percolation threshold (Wang, et al., 2015). Other study reported by Noël et al. (2014) has demonstrated high electrical conductivity with $700 \mathrm{Sm}-1$, of graphene-latex nanocomposites with a low percolation threshold (0.12\%vol) (Noel, et al., 2014).

Herein, CNCs isolated from oil palm empty fruit bunches (OPEFB) are mixed with CNTs via ultrasonicator resulting the CNCs@CNTs nanohybrid. These materials are studied to explain the affect of percolation approach in mechanical properties of nanocomposites. Then they are mild-mixed with NRL and the currative agents obtaining Latex/CNCs@CNTs nanocomposites. Morphology and physical properties (swelling index and crosslink density) are characterized in this work as well.

\section{Materials And Methods}

\subsection{Materials}

High ammonia natural rubber latex (HA-NRL) was supplied by PT. Industri Karet Nusantara, Deli Serdang, Sumatera Utara, Indonesia with dry rubber content (DRC) of $60 \%$. Sulphur, zinc oxide ( $\mathrm{ZnO})$, tetramethylthiuram disulfide (TMTD), and potassssium hydroxide (KOH) as curative agents for prevulcanization process of NRL were purchased from Merck Indonesia. Multi-walled carbon nanotube (MWCNT) powder with $\geq 98 \%$ carbon basis and O.D x I.D x L $10 \mathrm{~nm} \pm(1 \mathrm{~nm} \times 4.5 \mathrm{~nm} \pm 0.5 \mathrm{~nm} \times 3 \sim 6 \mu \mathrm{m})$ was acquired from Sigma Aldrich Singapore. Empty fruit bunches as raw material for producing CNC was collected from PTPN IV Adolina, Serdang Bedagai, Indonesia. Sodium hydroxide $(\mathrm{NaOH})$, acetic acid $(\mathrm{CH} 3 \mathrm{COOH})$, sodium hipochlorite $(\mathrm{NaOCl})$, hydrogen peroxide $(\mathrm{H} 2 \mathrm{O} 2) 30 \%$, and sulphuric acid $(\mathrm{H} 2 \mathrm{SO} 4)$ $98 \%$ used for isolating $\alpha$-cellulose and $\mathrm{CNC}$ were bought from Merck Indonesia.

\subsection{Isolation of $\alpha$-Cellulose from Oil Palm Empty Fruit Bunches (OPEFB)}

OPEFB was cutted into $10 \mathrm{~cm}$ length and washed with distilled water to clean up the dirt. After being cleaned, it was soaked into water overnight and dried in an oven at $80{ }^{\circ} \mathrm{C}$. About $75 \mathrm{gr}$ of dried OPEFB was treated with $1 \mathrm{~L}$ of $2 \% \mathrm{NaOH}$ and stirred for $4 \mathrm{~h}$ at $100{ }^{\circ} \mathrm{C}$. Next, 
they were filtered, washed until the neutral $\mathrm{pH}$ was reached and bleached with $1 \mathrm{~L}$ of mixture solution of acetic acid buffer and $1.7 \% \mathrm{NaOCl}$ (ratio $1: 1$ ) at $80{ }^{\circ} \mathrm{C}$ for $6 \mathrm{~h}$. After that, the bleached OPEFB was filtered and washed with distilled water until neutral (Silverio, et al., 2013).

To separate $\alpha$-cellulose from $\beta$ and $\gamma$-cellulose, the dried bleached OPEFB was soaked into $17.5 \% \mathrm{NaOH}$ at $80{ }^{\circ} \mathrm{C}$ for $30 \mathrm{~min}$. This mixture was then filtered, washed with distilled water until $\mathrm{pH}$ was neutral, the bleaching process was repeated with $10 \% \mathrm{H} 2 \mathrm{O} 2$ for 15 min at $60{ }^{\circ} \mathrm{C}$. Finally, it was dried in an oven at $60^{\circ} \mathrm{C}$ and was kept in vacuum desiccators (Ohwoavworhua and Adelakun, 2005).

Do not add any text to the headers (do not set running heads) and footers, not even page numbers, because text will be added electronically.

For a best viewing experience the used font must be Times New Roman, on a Macintosh use the font named times, except on special occasions, such as program code (Section 2.3.7).

\subsection{Treatment for Isolating Cellulose Nanocrystals (CNCs)}

Each gram of $\alpha$-cellulose was hydrolyzed using $15 \mathrm{~mL}$ of $48 \% \mathrm{H} 2 \mathrm{SO} 4$ at $45^{\circ} \mathrm{C}$ for $1 \mathrm{~h}$, then 10 fold of distilled water were added to stop the hydrolysis process. This was neutralized using ultracentrifuge for $15 \mathrm{~min}$ at $10,000 \mathrm{rpm}$ of speed and the sediment was homogenized using ultrasonic bath for $15 \mathrm{~min}$. The solid was dialyzed in dialysis membrane for 8 days in distilled water to remove the exceed sulphate groups and re-homogenized using ultrasonic bath for $15 \mathrm{~min}$. Finally, it was stored in refrigerator at $4^{\circ} \mathrm{C}$ (Silverio, et al., 2013).

\subsection{Percolating CNCs with CNTs Via Ultrasonic Method}

In this study, CNCs were percolated by CNT resulting CNCs@CNTs nanohybrid using ultrasonicator. $20 \mathrm{mg}$ of CNTs were dispersed in CNC solution (containing $20 \mathrm{mg}$ of CNCs in $100 \mathrm{~mL}$ distilled water) then sonicated for $12 \mathrm{~h}$ at room temperature to obtain CNCs@CNTs nanohybrid (Wang, et al., 2016).

\subsection{Fabrication of Latex/CNCs@CNTs Nanocomposites}

Prevulcanized NRL and CNCs@CNTs nanohybrid suspension were mixed on mild stirring for $2 \mathrm{~h}$ and demulsified with $200 \mathrm{~mL}$ of $1 \mathrm{M} \mathrm{H} 2 \mathrm{SO} 4$. The ratio between NRL, curative agents, and CNCs@CNTs nanohybrid suspension were shown in Table 1 below. This solid was filtered and soaked into distilled water to remove the exceed $\mathrm{H} 2 \mathrm{SO} 4$, then it was oven dried at $60^{\circ} \mathrm{C}$ for $24 \mathrm{~h}$. Finally, it was pressed using hydraulic hot press at $150^{\circ} \mathrm{C}$ for $5 \mathrm{~min}$ [5].

Table 1.Formulation of Prevulcanized Natural Rubber Latex and Latex/CNCs@CNTs Nanocomposites.

\begin{tabular}{ll}
\hline Material & Phr \\
\hline Natural Rubber Latex (NRL) & 100 \\
$50 \%$ Sulphur & 1.8 \\
$\% 0 \%$ TMTD & 1.8 \\
$10 \%$ KOH & 1.8 \\
$50 \%$ ZnO & 0.5 \\
CNCs@CNTs Nanohybrid & $1 ; 2 ; 3 ; 4 ; 5$ \\
\hline
\end{tabular}




\subsection{Characterization}

Mechanical properties of natural rubber latex/CNCs@CNTs nanocomposites were measured by Instron 5567 testing machine at $50 \mathrm{~mm} / \mathrm{min}$ of speed at room temperature. The sample length between jaws was $20 \mathrm{~mm}$ and the width was $10 \mathrm{~mm}$. Morphology of nanocomposites was observed by scanning electron microscopy (SEM) Hitachi S3400N Japan. Swelling index testing was determined using ASTM D3616, where the samples were weighed and immersed in pure toluene at room temperature for $24 \mathrm{~h}$. Then, the solvent on swollen samples surface was removed using filter paper, and the swollen samples were weighed. Toluene was removed from swollen samples by oven drying at $80^{\circ} \mathrm{C}$ until constant weight was reached, and thefinal weight was measured. The equation of swelling index $(\mathrm{Q})$ was counted as:

$$
\text { Swelling Index }(S I)=\frac{W_{2}-W_{1}}{W_{1}}
$$

\section{Result And Discussion}

\subsection{Mechanical Properties}

Mechanical behaviour of prevulcanized NRL and NRL/CNCs@CNTs nanocomposites have been tested to determine three aspects, they were tensile strength, Young's modulus, and elongation at break of each sample. The data could be seen on table 2 and the stress-strain curves were shown on figure 1 below as well.

Table 2.Tensile Properties of Prevulcanized NRL and NRL/CNCs@CNTs Nanocomposites.

\begin{tabular}{llll}
\hline Sample & $\begin{array}{l}\text { Tensile Strength } \\
(\mathrm{MPa})\end{array}$ & $\begin{array}{l}\text { Young's Modulus } \\
(\mathrm{MPa})\end{array}$ & $\begin{array}{l}\text { Elongation at } \\
\text { Break (\%) }\end{array}$ \\
\hline Prevulcanized & 0.31 & 0.44 & 218.70 \\
NRL & & 0.26 & 196.40 \\
NRL/CNCs@CN & 0.22 & 0.69 & 217.00 \\
Ts (1 phr) & & 0.46 & 167.01 \\
$\begin{array}{l}\text { NRL/CNCs@CN } \\
\text { Ts (2 phr) }\end{array}$ & 0.33 & & 385.60 \\
NRL/CNCs@CN & 0.43 & 0.09 & \\
Ts (3 phr) & & & \\
NRL/CNCs@CN & 0.34 & & \\
Ts (4 phr) & &
\end{tabular}

Based on the Table 2 above, NRL loaded by CNCs@CNTs nanohybrid were able to increase the number of tensile strength from 0.22 to $0.43 \mathrm{MPa}$, which the highest number of tensile strength, $0.43 \mathrm{MPa}$, was exhibited on NRL nanocomposite filled with $3 \mathrm{phr}$ of CNCs@CNTs. On the other hand, Young's modulus and elongation at break on pre-vulcanized NRL and NRL/CNCs@CNTs nanocomposites were observed fluctuate where maximum numbers of 
each category were respectively $0.69 \mathrm{MPa}$ for NRL/ CNCs@CNTs (3 phr) and 385\% for NRL/CNCs@CNTs (4 phr).

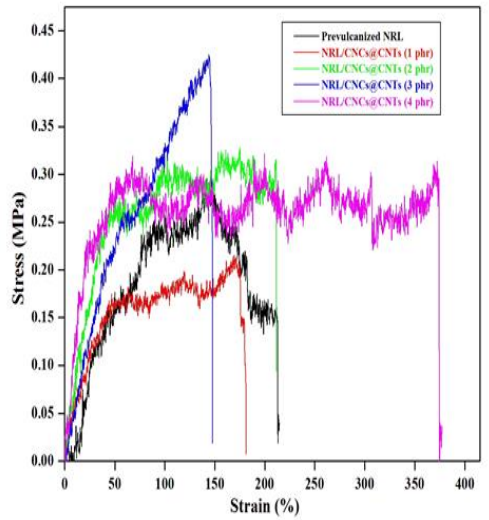

Figure 1.Stress-Strain Curves of Prevulcanized NRL and NRL/CNCs@CNTs Nanocomposites.

Figure 1 performed the curves of stress versus strain on pre-vulcanized NRL and NRL/CNCs@CNTs nanocomposites. From the curves, it could be understood that by loading CNCs@CNTs nanohybrid into NRL, the number of stress and strain could increase significantly. The stress were increase up to 0.1 point for each sample tested and the greatest number of stress, $0.43 \mathrm{MPa}$, were belonged to NRL/CNCs@CNTs (3 phr). Move on to the strain, it could be noticed that by filling the NRL with CNCs@CNTs nanohybrid could decrease the strain number and only adding $4 \mathrm{phr}$ of the fillers could raise the strain to the number of $385 \%$.

\subsection{Mechanical Properties}

SEM analysis was measured to analyze the morphology of the surface from the material. In this work, pre-vulcanized NRL and NRL/CNCs@CNTs nanocomposites have been characterized and the result was shown on Figure 2 below

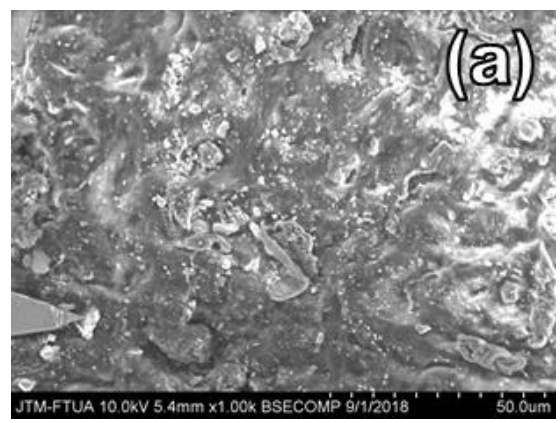




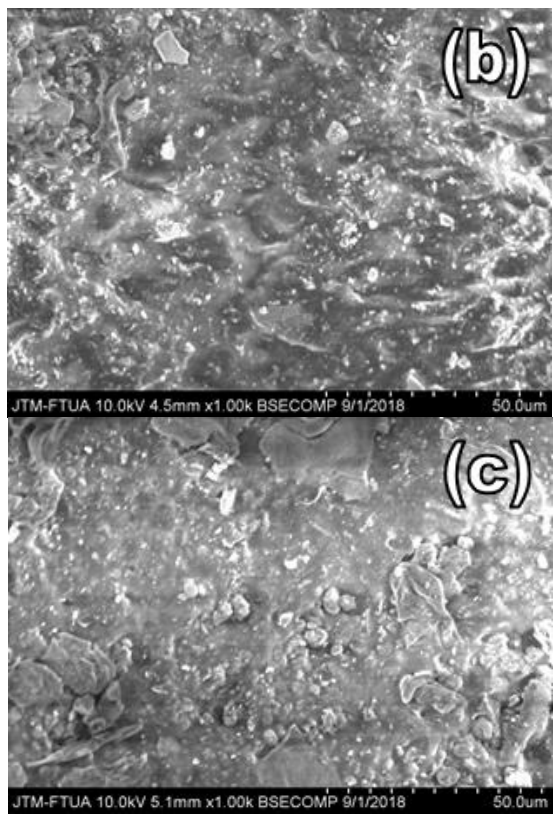

Figure 2.SEM Images of (a) Prevulcanized NRL, (b) NRL/CNCs@CNTs (3 phr), and (c) NRL/CNCs@CNTs (1 phr)

The images exhibited the surface of pre-vulcanized NRL and NRL/CNCs@CNTs nanocomposites filled by 1 and $3 \mathrm{phr}$ of fillers and it could be depicted that the most regular surface was captured on NRL/CNCs@CNTs ( 3 phr). This result was related to the number of tensile strength which this nanocomposite was also owned the best mechanical properties of all. The particles of the curative agents and latex were seen on those three pictures; however, distribution of the particles on pre-vulcanized NRL and NRL/CNCs@CNTs (1 phr) were not as well as NRL/CNCs@CNTs (3 phr) had. The particles were not well-distributed on the prevulcanized NRL surface due to the mixing time that was only $2 \mathrm{~h}$, compared with the nanocomposites which had $1 \mathrm{~h}$ for blending with the filler after having $2 \mathrm{~h}$ of time mixing with the curatives. On the surface of NRL/CNCs@CNTs (1 phr), it can be noted the agglomeration of the particles was occurred and this caused the number of tensile strength declined.

\subsection{Swelling Properties}

Swelling test was conducted to measure the resistance of NRL-based nanocomposites immersed in a solvent. In this work, the solvent was toluene and the numbers of swelling index of the samples were illustrated on table 3 below. 
Table 3.Swelling Index of NRL Filled by CNCs@CNTs.

\begin{tabular}{ll}
\hline CNCs@CNTs Loading (phr) & Swelling Index \\
\hline 0 & 9.98 \\
1 & 9.64 \\
2 & 9.24 \\
3 & 8.6 \\
4 & 9.05 \\
\hline
\end{tabular}

The table showed swelling number of NRL loaded by 0 to 4 phr of CNCs@CNTs nanohybrid. The number of swelling index consisted of $0 \mathrm{phr}$ of fillers were 9.98 and it was going to decline to 8.6 for 3 phr of CNCs@CNTs which was the minimum number of whole measured samples; however, this number moved up to 9.05 at 4 phr fillers of nanocomposites.

The decline of swelling index on pre-vulcanized NRL and NRL/CNCs@CNTs nanocomposites could be also seen on figure 3 below.

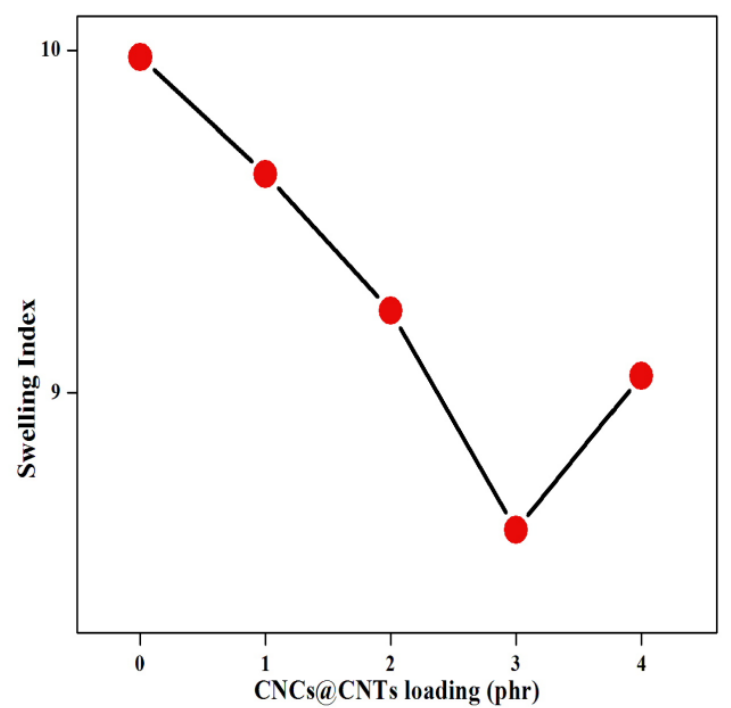

Figure 3.Swelling Index Curves of Pre-vulcanized NRL and NRL/CNCs@CNTs Nanocomposites

A material could swell in a solvent due to the solvent molecules diffused into the material. This was happened to the samples in this work where they swelled after immersing in toluene, the solvent, for $24 \mathrm{~h}$. For pre-vulcanized NRL which the fillers were not contained, it presented the highest number of swelling index; however, by filling the pre-vulcanized NRL with the fillers, CNCs@CNTs nanohybrid, this number was going down. From this phenomenon, it could be noticed that the fillers interacted and resisted the rubber in NRL so the molecules of the solvent could not diffused into thenanocomposites as much as prevulcanized NRL occurred. 


\section{Conclusion}

The mechanical properties improvement on NRL nanocomposites filled with CNCs percolated by $\mathrm{CNTs}$ has been demonstrated. By using ultrasonic method, CNCs was mixed with CNTs and obtained the CNCs@CNTs nanohybrid. This nanohybrid was incorporated with pre-vulcanized NRL by mild mixing method resulting NRL/ CNCs@CNTs nanocomposites. The NRL/CNCs@CNTs nanocomposites showed enhancement of tensile strength $(0.22$ to $0.43 \mathrm{MPa})$ and the regularity of particle distribution on the surface of the nanocomposites. Furthermore, the more fillers filled the nanocomposites, the lower swelling index achieved.

Acknowledgement.The authors gratefully thank to the Rector of University of Sumatera Utara, Medan, Indonesia, for the financial support via "Penelitian Dasar Unggulan Universitas Talenta Project 2018" scheme.

\section{References}

[1]Noel, A., Faucheu,J., Chenal,J. M., Viricelle, J. P. and Lami,E. B.: Electrical and Mechanical Percolation In Graphene-Latex Nanocomposites,Polymer, 55,pp. 5140-5145 (2014)

[2]Meng, Q. and Zloczower,I. M.: Carbon Nanotubes Enhanced Cellulose Nanocrystals Films With Tailorable Electrical Conductivity. Composites Science and Technology,120, pp. 1-9 (2053)

[3]Ohwoavworhua, F. O.and Adelakun,T. A.: Phosporic Acid-Mediated Depolymerization and Decrystallization of a-Cellulose Obtained From Corncob: Preparation of Low Crystallinity Cellulose and Some Physicochemical Properties,Tropical Journal of Pharmaceutical Research, 4(2), pp. 509$516(2005)$

[4]Roberts, A. D.: Natural Rubber Science and Technology. Oxford University Press, Oxford (1988) [5]Silverio, H. A., Neto, W. P. F., Dantas, N. O. and Pasquini,D.: Extraction and Characterization of Cellulose Nanocrystals from Corncob for Application as Reinforcing Agent in Nanocomposites,Industrial Crops and Products, vol. 44, pp. 427-436 (2013)

[6]Wang,S., Zhang, X., Wu, X. and Lu,C.: Tailoring Percolating Conductive Networks of Natural Rubber Composites for Flexible Strain Sensors Via a Cellulose Nanocrystal TemplatedAssembly," Soft Matter, 12, pp. 845-852. (2016) 